\title{
Prion disease scare
}

London. For the past ten days, Britain has been plagued by anxiety over prion disease largely because cases of Creutzfeldt-Jakob disease (CJD) have been linked to the use of pituitary and other material taken from cadavers. The anxiety has sprung from two separate causes. The more predictable has been the use of hormones extracted from cadaver pituitaries between 1956 and 1985 , since when synthetic material has been used.

More surprising is the practice in neurosurgery of using a lyophilized preparation of outer brain-case membranes taken from cadavers as packing in the skull after brain surgery. The material used, trade-marked Lyodura, is manufactured by Braun Melsungen AG in Germany, but has not been used in Britain since its licence was withdrawn in 1991.

The latest anxiety has also been strengthened by fears that bovine spongiform encephalitis (BSE), still prevalent among British cattle, may yet appear as CreutzfeldtJakob disease in people.

Of the hormones extracted from pituitaries, the use of human growth hormone is the longest established. A project at the Institute of Child Health in London has been commissioned to trace the estimated 2,000 adults who were treated with the hormone as children or young adults.
The more recent use of pituitary gonadotrophin as a treatment for female infertility has thrown up more immediate problems for the British Department of Health, notably with publicity for four cases in Australia of women developing CJD after treatment with pituitary hormone.

In the early days, the extraction of hormones seems to have been the responsibility of the Medical Research Council, and was carried out at a Cambridge laboratory. Becausie pituitary extracts were pooled, neither batch numbers nor other identifiers survive to guide the search for people who may have been infected.

Meanwhile there is little to report on the BSE front. The rate of infection among cattle has not begun to fall, as the Southwood report in 1986 predicted it would have done by now. A committee under Dr David Tyrrell is now monitoring developments. But an interim report last year found no basis for changing the present policy of seeking to restrict the infection of cattle by the rigorous avoidance of sheep offal in cattle feed.

Although it is accepted that CJD and BSE are essentially similar, and that both are prion diseases (as is scrapie in sheep), there has not been unambiguous evidence of transspecific infection of a person with CJD. On the other hand, British policy on cattle ex- plicitly acknowledges that transfer can occur between sheep and cattle.

The position seems to be what it has been for some months. The protein part of the prion entity is known to be a normal part of the human genome (on chromosome 20), which is inserted in the outer membrane of neurons and certain other cells. Its function is unknown. A strain of mice bred to lack the gene was found last year (Nature 356, 577; 1992) to develop apparently normally, at least for seven months.

The course of prion disease is accompanied by the accumulation of an aberrant form of the protein within vesicles in the cell. In what way these molecules differ from the protein that remains anchored to the outer membrane is not yet known, nor is there any clear indication whether the normal or abnormal prion protein may be loosely associated with other entities, perhaps nucleic acid polymers.

The sheep, mouse and human prion proteins are all very similar, but the process of logging mutations of the human gene is no doubt far from complete. One intriguing feature of the known mutations of the human prion protein gene is that some are marked by the appearance of up to 9 eightcodon (24 nucleotide) repeats in a region near the front end of the gene already replete with them. But there is as yet no clear link between the structure of the gene and either the mechanism or susceptibility to disease.

John Maddox

\section{More graduates - but fewer jobs}

London. Britain's universities are producing more science and engineering graduates than ever before, according to figures released last week by the Universities Statistical Record. But at the same time the number of such graduates finding jobs in industry has been falling sharply, suggesting that the lack of trained scientists in the work-force remains, at least for the present, a problem of demand rather than supply.

The latest figures show that, contrary to widespread impressions in the media, the number of UK-based students graduating in science subjects rose by 7.6 per cent between 1991 and 1992, following a 3.0 per cent decrease the previous year. This news should temper much of the gloom caused two weeks previously by news of a continued decline in the proportion of school students taking science subjects at A level.

The trends for the physical science are typical. The number taking A-level physics dropped by about 10 per cent between 1992 and 1993. But the number of UK-based physics graduates increased by 7.6 per cent between the summers of 1991 and 1992.

For physical science as a whole (which also includes fields such as chemistry and geology), the increase in graduates was even greater, at 11.1 per cent.

In contrast - and more worrying - was the smaller increase of 3.4 per cent of graduates in engineering and technical subjects. And the employment situation paints a bleaker picture. Over the same period, the proportion of physical science graduates entering industry fell from 44 per cent to 37 per cent, a bigger decrease than that experienced by graduates in any other academic discipline, either in the arts or the sciences.

UK-based graduates from British universities 1989 - 92 (in thousands)

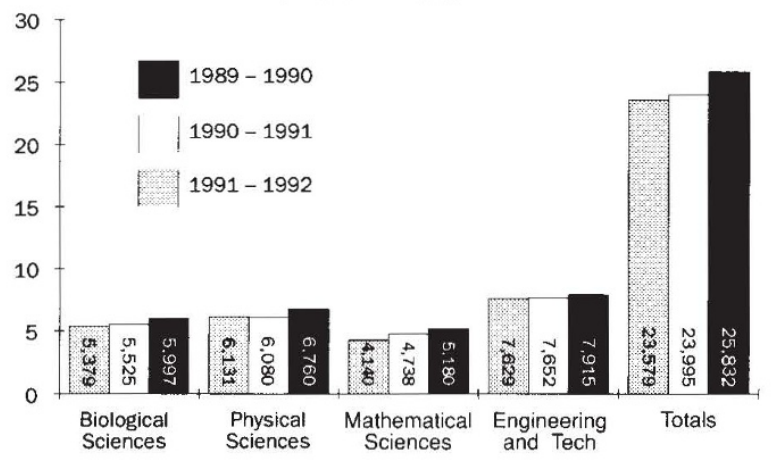

This fall was partly compensated for by the increased proportion (32 per cent compared to 28 per cent) entering careers in commerce. Nevertheless, by the end of December last year, 12.3 per cent of physical science graduates were still unemployed (compared, for example, with only 9.7 of social science graduates).

This overall trend is reflected in figures being reported by industry itself. Last week, for example, the Chemical Industries Association (CIA) produced its annual survey of graduate recruitment, which showed that the number of graduates recruited by the industry fell by 16 per cent between 1991 and 1992.

In the near term, the difficult economic climate means that the prospects for science graduates remain bleak. The CIA survey says that companies expect their recruitment to fall by a further 24 per cent this year. But, in the longer term, 90 per cent said that they believed demand for graduates would either improve or remain static, and almost half expected the demand for certain types of graduates to increase.

David Dickson 